\title{
MIGRAÇÃO DE LMS: IMPACTOS E DESAFIOS NA BUSCA PELA EXCELÊNCIA
}

\author{
RIO DE JANEIRO/RJ JUNHO/2018
}

\author{
Diana Abreu - FGV - diana.abreu@fgv.br \\ Flavio Camargo - FGV - flavio.camargo@fgv.br \\ Vanessa Mizuta - FGV - vanessa.mizuta@fgv.br
}

Tipo: Relato de Experiência Inovadora (EI)

Categoria: Métodos e Tecnologias

Setor Educacional: EDUCAÇÃO SUPERIOR

\begin{abstract}
RESUMO
O presente artigo é um relato de experiência promovido pela coordenação de Tecnologias Educacionais em uma Escola de Nível Superior com cursos de Graduação Tecnológica. Descreveremos a seguir nossa experiência com a migração das disciplinas dos cursos de: Gestão comercial, Gestão Financeira, Gestão Pública, Processos Gerenciais e Marketing. Neste artigo evidenciaremos como se deu a migração das disciplinas, dos cinco cursos online de graduação de um ambiente virtual para outro. Neste relato apresentaremos nosso planejamento inicial, o histórico anterior, nossas aspirações por essa migração, bem como os gargalos, algumas dificuldades encontradas, a necessidade de mudança e a solução proposta. Abordaremos também a motivação da equipe gestora por esta migração, aspectos que foram mapeados anteriormente. Por fim, apresentaremos nossas considerações finais, os resultados obtidos, as lições aprendidas e os caminhos traçados para o futuro.
\end{abstract}

Palavras-chave: Educação e tecnologia, ambientes virtuais, relato de experiência, educação superior 


\section{Reflexões sobre Educação e Tecnologia}

"O conhecimento não pode ficar restrito ao simples aprendizado adquirido nas tradicionais salas de aula; só o exame crítico desse conhecimento leva à descoberta. É preciso buscar novas dimensões para uso de tecnologias, através de uma visão democrática e coerente da realidade brasileira" (Léa Silvia Mende).

A educação tem hoje em mãos a difícil tarefa de se adequar a realidade tecnológica vivida por toda a sociedade, a diferença no uso da tecnologia é sutil na maioria dos contextos sociais nos tempos atuais, algumas pessoas usam mais outras menos, mas todas as gerações e classes utilizam de alguma maneira a tecnologia no seu dia a dia, mesmo que algumas ainda de forma precária. A cultura tecnológica ganhou espaço no cotidiano das pessoas de todas as idades, sem restrição. No entanto, no âmbito da educação a tecnologia, ainda, luta para acompanhar os avanços que a sociedade vive em outras esferas. Buscamos continuamente um espaço para a apropriação da tecnologia nas práticas pedagógicas e educacionais.

$\mathrm{Na}$ escola contemporânea não basta levar a sala de aula tradicional para um ambiente virtual, é preciso ir além. As mudanças culturais trazidas pelas denominadas sociedades em rede[1] e pela Cibercultura[2] afetaram a estrutura social. Essa mudança cultural descortinou uma nova realidade, onde a relação com o saber se modificou e com isso, novas formas de interação com a informação e entre as pessoas foram naturalmente estabelecidas e guiadas pela própria tecnologia. Para a educação moderna é necessário aproximar o real do virtual, e estabelecer novas formas de relação com o saber, aumentar a troca, diminuir a distância e se beneficiar das ferramentas disponíveis para estreitar a comunicação.

Neste cenário as Tecnologias de Comunicação e Informação se colocam no papel fundamental de oferecer ferramentas, apoiar e dar suporte para o estudante no seu processo de aprendizagem, na construção do conhecimento e na sua formação acadêmica. $O$ uso de ferramentas de qualidade, que integrem recursos de comunicação e interação entre professores e alunos, acesso à conteúdos diversos da universidade e da biblioteca digital, ajudam a garantir uma experiência educacional rica de significados. Nessa perspectiva o aluno que hoje é exposto a um oceano de conteúdos na web sai do papel passivo e assume o direcionamento do seu processo de construção, onde estudar deixa de ser, somente, seguir programas previamente definidos e passa a ser impulsionado, prioritariamente, pelo seu desejo de aprender sobre algo que faça sentido para sua vida. Pensando nisso nos colocamos continuamente na missão de buscar ferramentas de qualidade e rica em diversos recursos que proporcionem tal experiência de aprendizagem para nossos alunos. 


\section{Relato de experiência}

O presente artigo apresenta um relato de experiência inovadora desenvolvida em cinco cursos de graduação tecnológica, na Escola Brasileira de Administração Pública e de Empresas - EBAPE, da Fundação Getúlio Vargas - FGV na cidade do Rio de Janeiro, ano de 2017 e início de 2018. Nesta experiência, foram migrados os cursos de Gestão comercial, Gestão Financeira, Gestão Pública, Processos Gerenciais e Marketing, do Ambiente Virtual de Aprendizagem - AVA Moodle para o D2L by Brightspace.

\section{Contextualização}

A FGV há muito tempo tem feito uso de tecnologias educacionais para apoiar suas aulas presencias e também para ofertar cursos a distância com o objetivo de oferecer uma experiência educacional de qualidade e com diversos recursos que proporcionem uma vivência produtiva e um processo de aprendizagem enriquecedor. Um dos principais recursos tecnológicos utilizado pela FGV, que viabiliza o processo de construção de conhecimento e a colaboração são os Ambientes Virtuais de Aprendizagem - AVA.

Segundo o Ministério da Educação (2007), os Ambientes Virtuais de Aprendizagem são: Programas que permitem o armazenamento, a administração e a disponibilização de conteúdos no formato Web. Dentre esses, destacam-se: aulas virtuais, objetos de aprendizagem, simuladores, fóruns, salas de bate-papo, conexões a materiais externos, atividades interativas, tarefas virtuais (webquest), modeladores, animações, textos colaborativos (wiki). Podemos afirmar que os AVAs permitem a criação de uma extensão virtual da sala de aula física tanto para os cursos presencias quanto para os cursos semipresenciais, tornando-se uma poderosa opção de ferramenta para mediar o processo ensino e aprendizagem, realizado a distância. Segundo MCKIMM, JOLLIE e CANTILLON (2003 apud PEREIRA 2007, p. 6):

Consiste em um conjunto de ferramentas eletrônicas voltadas ao processo ensino-aprendizagem. Os principais componentes incluem sistemas que podem organizar conteúdos, acompanhar atividades e, fornecer ao estudante suporte on-line e comunicação eletrônica.

Ao longo dos anos muitos AVAs, proprietários e desenvolvidos internamente, foram utilizados pela FGV. Até dezembro de 2014 eram mantidos cinco ambientes virtuais diferentes, sendo que cinco escolas compartilhavam um mesmo AVA, outras três escolas usavam cada uma um AVA distinto e os cursos a distância usavam um AVA próprio. Este artigo relata o processo de migração dos cursos do tecnólogo ocorrido na Escola Brasileira de Administração Pública e de Empresas (EBAPE), sendo assim focaremos na experiência da escola no uso dos AVAs. A EBAPE tem experiência com o 
uso do AVA, para apoiar suas aulas presenciais, desde 2006 quando internamente 0 setor de tecnologia da escola desenvolveu um AVA simples para compartilhar arquivos e troca de trabalhos entre alunos e professores.

A EBAPE era uma das quatro escolas que compartilhava um mesmo Ambiente Virtual e tinha uma experiência bem-sucedida em seu uso, porém, haviam as Graduações Tecnológicas, oferecidas na modalidade EAD que utilizavam a plataforma Moodle. Vale ressaltar que este Moodle em especifico era uma das primeiras versões lançadas desta plataforma e que seu "core" foi tão alterado e customizada que já não se podia aplicar atualizações de versões recentes. As customizações realizadas ao longo dos anos alteraram tanto o core do Moodle que descaracterizou sua essência, ao ponto de ser percebido por muitos como uma plataforma praticamente desenvolvida pela FGV. No final de 2014 a FGV optou, após uma vasta pesquisa de mercado, adquirir um novo Ambiente Virtual de Aprendizagem visando padronizar a plataforma e oferecer para todas as escolas e cursos um Ambiente único com as mesmas ferramentas de interação e recursos e para os alunos a mesma experiência educacional no AVA. O AVA escolhido foi o Brightspace, intitulado como ECLASS para não vincular com o nome comercial. Este novo nome faz alusão a um dos AVA antigo e que era mais difundido na FGV. A implementação do Brightspace implicou em uma intensiva homologação envolvendo técnicos, analistas, corpo docente e outros agentes estrategicamente selecionados, além de uma comunicação e oferta de oficinas de capacitação para suprir todas as necessidades dos usuários da nova plataforma. Após o sucesso da implantação das escolas e de muitos cursos a distância, em 2017 decidiu-se por migrar do Moodle para o ECLASS os cinco cursos da Graduação Tecnológica.

\section{A Migração e seus desafios}

Além da migração representar um avanço tecnológico, tendo em vista que o Ambiente Virtual utilizado, anteriormente, já estava sem passar por update de versão a muitos anos, ela também resolveria questões técnicas, viabilizaria uma entrega tecnológica mais robusta e completa para nossa sociedade acadêmica. O AVA utilizado havia se tornada um sistema insuficiente para atingir o nosso objetivo, no que tange o potencial tecnológico, a estabilidade, a segurança e a interação síncrona entre professores, tutores e alunos.

Para a realização do processo de migração de todos os cursos tecnólogos da EBAPE, que eram oferecidos no Moodle customizado da FGV e foram migrados para o ECLASS, primeiramente foram levantados o número de disciplinas existentes e feito um estudo minucioso de todos os recursos que eram utilizados em cada curso e cada disciplina. Foi 
verificado que na primeira etapa seriam migradas 30 disciplinas, as quais faziam uso não só dos recursos nativos do Moodle, como também de SCORMs para alguns conteúdos e um sistema customizado para o cálculo de nota. Além disso, o sistema de backup e restauração dos AVAs não eram compatíveis o que exigiu uma migração manual dos conteúdos e a recriação de recursos como: questionários, pesquisas, calendários, fóruns entre outros. Foi constatado que os históricos de envios de atividades, participação em fóruns de discussão, notas, chats e pesquisas, não seriam possíveis de migrar. Sendo que como estratégia mantivemos o AVA antigo por um certo período, somente para consulta e resgate de materiais para os alunos e tutores. Alertando-os que depois desse período não seria mais possível o acesso ao AVA.

Muitas áreas da FGV foram envolvidas para viabilizar as integrações necessárias, a Coordenação de Tecnologias Educacionais (CTE), a Secretaria Acadêmica (SRA), a Coordenação dos cursos Tecnólogos e a equipe responsável pela gestão técnica do Sistema Acadêmico, cada uma atuou dentro do seu escopo para garantir que todas as integrações necessárias fossem concluídas com sucesso. Sendo assim, no processo de migração a Coordenação de Tecnologias Educacionais ficou responsável pela criação e estruturação das disciplinas no ECLASS, pela capacitação dos tutores no novo Ambiente Virtual e pela migração de todos os conteúdos. Para essa última atividade foi necessário tratar os arquivos em HTML que usavam links absolutos e não dinâmicos e alterar as templates dos conteúdos que apresentavam informações redundantes na interface. Para otimizar esse trabalho, que possui grande demanda, foi desenvolvido um script na linguagem PHP que verifica as linhas de códigos dos arquivos, este script faz os devidos ajustes automaticamente.

A equipe de Gestão do Sistema Acadêmico responsável pelo desenvolvimento das cargas de disciplinas, alunos, tutores e professores foi envolvida para realizar todas as alterações necessárias para a contemplação da criação das disciplinas via o Sistema de Registro Acadêmico (SRA) e o envio das notas das disciplinas contidas no AVA, que compunha a média online, para o SRA. A equipe da coordenação dos tecnólogos ficou responsável por toda recriação dos recursos como atividades, fóruns, rubricas, pesquisas, calendário etc e homologação de todo trabalho final de carga e de conteúdo. Após 4 meses de trabalho intenso as 30 disciplinas foram migradas para o ECLASS, porém havíamos um outro problema a ser solucionado. Quando há a oferta das disciplinas para os alunos são criadas turmas para dividi-los devido a relação de números de alunos por tutores. Muitas disciplinas são oferecidas várias vezes de acordo com o número de turmas existentes, por exemplo, a disciplina de Contabilidade Geral pode ser oferecida para 5 turmas diferentes. Com este cenário imagine que após as aulas iniciarem é verificado uma alteração necessária de conteúdo. Neste caso seria 
necessário realizar a alteração nas 5 diferentes turmas no ECLASS. Para evitar tamanho trabalho nós desenvolvemos uma estrutura na qual usa-se uma disciplina modelo onde é hospedado todos conteúdos e recursos. Quando as turmas são criadas no AVA via carga é feito uma cópia de todo conteúdo da disciplina modelo para as turmas e se houver alguma alteração no conteúdo da modelo automaticamente é replicado para as outras turmas. Com essa estratégia o tempo despendido nas alterações diminuiu significativamente.

\section{Resultados Atingidos}

Os resultados deste projeto de migração foram atingidos com sucesso, foram 5 cursos de graduação, diversas disciplinas migradas e customizadas, professores e tutores capacitados no novo Ambiente Virtual, alunos migrados e sistemas integrados. Como não teríamos mão de obra suficiente para migrar todas as disciplinas antes do inicio do ano letivo, dividimos o projeto em fases, conforme gráfico 1. A primeira fase migramos todas as disciplinas que seriam ofertadas nos cinco cursos em 2018.1, demos continuidade em mais duas fases e concluímos um total de 84 disciplinas migradas até maio de 2018. Agora estamos customizando todas as disciplinas para que tenham uma cópia que será cadastrada no sistema acadêmico como disciplinas especiais, pois possuem algumas pequenas customizações de atividades ou notas.

Gráfico 1: Status de migração / início da oferta das disciplinas

Ao longo do processo de migração a equipe do CTE, realizou diversas oficinas online, com o objetivo de capacitar o grupo de staff da Secretaria, da coordenação dos cursos, os coordenadores, professores e tutores, para que no início do período letivo 2018.1 todo o corpo docente já estivesse capacitado para o uso da ferramenta e para orientação dos alunos. Foram capacitados uma media de 70 usuários entre staff, professores e tutores. Alguns professores e tutores não participaram, pois já conheciam a plataforma. Para início do primeiro semestre de 2018, carregamos todos os usuários conforme Gráfico 2, foram: 730 alunos ativos, 59 tutores e 11 professores. Estamos agora com o processo de carga de usuários alinhados e prontos para o inicio do segundo semestre de 2018.

\section{Gráfico 2: Usuários ativos no ECLASS}

Os principais problemas ocorridos nas primeiras semanas de aula, foram com login de usuários que possuíam credenciais tanto de aluno como de tutor ou professor e tutor, devido as credencias de outros sistemas corporativos da FGV, no entanto os ajustes no 
processo já foram concluídos. O uso da nova plataforma apresentou ganhos significativos, tanto em aspectos técnicos, quanto pedagógicos. Os aspectos técnicos em destaque: o uso de uma ferramenta institucional garante maior esforço na implementação de melhorias, na integração de diversos softwares que possam agregar valor ao processo pedagógico, na manutenção do sistema e sua sustentação, em um suporte técnico em níveis de atendimento: suporte da própria plataforma, suporte da área especialista na FGV e suporte Help Desk, garantindo um atendimento de qualidade para toda a sociedade acadêmica. Além disso, os aspectos pedagógicos representam antes de mais nada uma redução na distância entre professores, tutores, alunos e coordenação, por meio do uso de ferramenta de web conferência integrada, onde os tutores podem agendar suas próprias aulas online ou reunião virtual com sua turma, além disso a nova plataforma possui um software de verificação de plágio integrado ao LMS, que possibilita que o professor e/ou tutor possa verificar o relatórios similaridade dos trabalhos enviados, esse software busca desenvolver nos alunos ao longo dos cursos uma escrita original e não uma punição no caso de plágio.

O retrato atual do uso das ferramentas de interação do ECLASS, conforme gráfico 3, demonstra que para um período de 5 meses de uso, estamos indo no caminho certo, já possuímos um numero elevado interação no AVA, constando 23.952 tópicos de conteúdo, 22.146 posts no fórum de discussão. No entanto, ainda temos um caminho a ser percorrido para que as ferramentas da nova plataforma sejam incluídas no programa do curso e nas atividades pedagógicas.

Gráfico 3: Uso de Ferramentas de Interação

\section{Apontamentos ao final da experiência...}

Foi possível perceber que no planejamento de uma migração não basta checar o volume de disciplinas, os tipos e formatos de arquivos que serão migrados, essas são tarefas indispensáveis, mas aprendemos a importância de levar em consideração o conhecimento da equipe que se tem disponível, mapear e estimar a demanda levandose em consideração: o volume de disciplinas e recursos a serem migrados, o esforço necessário para integrações e ajustes em processos que rodavam normalmente e que, possivelmente, precisarão de ajustes para se tornar funcional, mapeamento dos requisitos e regras de negócio da coordenação do curso e das propostas pedagógicas previstas no programa, pois isso pode alterar a mecânica prevista no sistema, exigindo customizações ou novas configurações no AVA. Bem como estimar o tempo necessário para todas as atividades relacionadas a criação de disciplina modelo, migração e exportação dos arquivos, revisão, ajustes de material, ajustes no calendário da 
disciplina, e homologação.

Um exemplo disso é uma atividade fundamental que não foi contemplada e nos gerou problemas no início do projeto que é o mapeamento de perfis de acesso, permissões, e hierarquia de acessos, pois por mais que tenhamos feito o mapeamento não vislumbramos todos os cenários possíveis. Por conta disso enfrentamos problemas nos primeiros dias de acesso, com alguns tutores e coordenadores, que possuíam tanto login de coordenação, como de tutor, e alguns tutores que possuíam tanto login de tutor quanto de aluno e não sabiam qual login utilizar, mas rapidamente identificamos e solucionamos. Algumas disciplinas não apareciam, mesmo estando carregadas, identificamos que em alguns casos as regras de visualização precisavam ser alteradas manualmente. Mesmo tendo realizado diversos teste no ambiente de homologação, quando fomos para o ambiente de produção enfrentamos estas questões.

\section{Referências}

CASTELLS, M. A Sociedade em Rede. A era da informação: economia, sociedade e cultura volume I, São Paulo, Editora Paz e Terra, 1999a

EHLERS, D. (2009). Web 2.0 - e-learning 2.0 - quality 2.0? Quality for new learning cultures, Quality Assurance in Education, 17, 3, 296 - 314.

BARROSO, Julio. Replanteando el e-learning: hacia el elearning 2.0, Campus Virtuales, no 02, v. II, 2013, Revista Científica de Tecnología Educativa; ISSN: 2255-1514

LEVY, Pierre. Cibercultura, Rio de Janeiro: Editora 34, 1999.

MATTAR, João. Educação e Tecnologias: refletindo e transformando o cotidiano. 1. Ed. - São Paulo: Artesanato Educacional, 2017.

MCKIMM, J; JOLLIE, C.; CANTILLON, P. ABC of learning and teaching - Web based learning. eb based learning BMJ 2003;326:870-873. Disponível em: http://bmj.com/cgi/content/full/326/7394/870\#otherarticles . Acesso em: 15/04/2018.

MESSA, Wilmara. Utilização de Ambientes Virtuais de Aprendizagem - AVAs: a busca por uma aprendizagem significativa. Disponível em: http://www.abed.org.br/revistacientifi ca/Revista_PDF_Doc/2010/2010_2462010174147.pdf Acesso em: 15/04/2018.

SANTOS, Santa Marli P. O lúdico na formação do educador. Rio de Janeiro: Vozes, 
2001.

SOBREIRO, Jason. Gamificação no Ensino médio e técnico: um relato de experiência. Artesanato Educacional. 2017.

[1] Sociedade em Rede - "A sociedade em rede, em termos simples, é uma estrutura social baseada em redes operadas por tecnologias de comunicação e informação fundamentadas na microelectrónica e em redes digitais de computadores que geram, processam e distribuem informação a partir de conhecimento acumulado nos nós dessas redes" (Castells, 2000, p.20).

[2] Cibercultura - "especifica aqui o conjunto de técnicas (materiais e intelectuais), de práticas, de atitudes, de modos de pensamento e de valores que se desenvolvem juntamente com o crescimento do ciberespaço" (LÉVY, 1999, p. 17). 